\title{
Metodologias variadas no ensino de ciências: um estudo com professores do município de Ibitirama - ES
}

Varied methodologies in science teaching: a study with teachers from the city of Ibitirama - ES

Manoel Augusto Polastreli Barbosa

Pedro José Garcia Júnior

\begin{abstract}
Resumo: Este trabalho objetivou analisar a utilização de metodologias variadas no ensino de Ciências das escolas do município de lbitirama pelos docentes que lecionam no Ensino Fundamental dos Anos Finais. A pesquisa é de natureza qualiquantitativa e exploratória, foi conduzida por meio de questionário, composto de questões de múltipla escolha. A partir do estudo realizado, identificou-se certa variação no uso dos recursos metodológicos utilizados no ensino de Ciências. Dada variação deve-se aos recursos disponíveis para uso nas escolas onde atuam e à necessidade de utilização de diferentes propostas didáticas. Desta forma, o presente estudo propõe a diversificação das aulas mediante a grande quantidade de fontes que o ensino de Ciências dispõe.
\end{abstract}

Palavras-chave: Metodologias Variadas. Ensino de Ciências. Professores.

Abstract: This study aimed to analyze the use of different methodologies in the teaching of Science in schools in the municipality of Ibitirama by teachers who teach in Elementary School in the Final Years. The research is qualitative-quantitative and exploratory, it was conducted through a questionnaire, consisting of multiple choice questions. From the study carried out, a certain variation in the use of methodological resources used in Science teaching was identified. This variation is due to the resources available for use in the schools where they work and the need to use different didactic proposals. Thus, this study proposes the diversification of classes through the large number of sources that science education has.

Keywords: Varied Methodologies. Science teaching. Teachers.

Introdução

De acordo com Brasil (2018), o ensino de Ciências deve propor aos alunos, variadas situações de aprendizagem partindo de questões que desafiem e estimulem os alunos, despertando a curiosidade científica, possibilitando assim a criação de problemas, o levantamento de hipóteses, a análise destas, bem como discutir sobre os resultados, buscando estimular a comunicação e representação dos resultados.

Através do processo investigativo que deve ser entendido como principal elemento na formação dos estudantes, e cujo desenvolvimento deve ser atrelado a situações didáticas planejadas ao longo de toda a educação básica, esse processo formativo deve ocorrer de modo a possibilitar aos alunos 
revisitar de forma reflexiva seus conhecimentos e sua compreensão acerca do mundo em que vivem.

Partindo do pressuposto, vê-se a necessidade de analisar a utilização de metodologias variadas do professor em sua prática pedagógica. Assim tem como objetivo analisar as metodologias utilizadas no ensino de Ciências das escolas de Ensino Fundamental do município de Ibitirama - ES.

\section{O ensino de ciências}

A Base Nacional Comum Curricular propõem para o ensino de Ciências conhecimentos de importância social, que possuam significado para os alunos e que sejam de valor científico e tecnológico (BRASIL, 2018).

De acordo com (BRASIL, 2018, p. 321):
A área de Ciências da Natureza, por meio de um olhar articulado de diversos campos do saber, precisa assegurar aos alunos do Ensino Fundamental o acesso à diversidade de conhecimentos científicos produzidos ao longo da história, bem como a aproximação gradativa aos principais processos, práticas e procedimentos da investigação científica.

Um dos meios para se dar início à busca pelo sucesso do processo de ensino aprendizagem em Ciências é a sondagem dos estudantes perante os temas científicos tratados, tomando a prática vivenciada pelos alunos como o enfoque inicial do planejamento e da implementação do currículo e do ensino, sendo esses pontos interessantes a serem considerados e, respectivamente, tratados pelo professor de Ciências (MALAFAIA; RODRIGUES, 2008).

De tal modo, deve-se estar atento quando se trata da formulação de atividades que não estejam de acordo com a realidade vivenciada pelos alunos, para que não haja distância entre os objetivos do que está sendo trabalhado no momento e o que o aluno realmente espera aprender. Tal caracterização de atividades pode levar a formação de alunos treinados a mera repetição de conceitos, aplicador de fórmulas e armazenador de termos, sem sequer ter a possibilidade de saber compará-los ou aplicá-los em seu cotidiano; possuindo, desta maneira, uma posição secundária, colocado em segundo plano, no processo de ensino aprendizagem, e não como um conhecimento 
colocado em construção, o que é o esperado (MALAFAIA; RODRIGUES, 2008).

Segundo Moura e Vale (2001), a ciência tida como pronta e acabada torna-se um impedimento de se construir conhecimento (que deveria ser construído gradualmente), extinguindo a visão do educando como sujeito do processo educativo.

As Ciências Naturais devem ser compreendidas como um projeto histórico, um conhecimento não debilitado, constituidor de um trabalho que oportuniza o ato de expressar dos indivíduos e resultante da ação coletiva de uma produção em grupo (DELIZOICOV; ANGOTTI; PERNAMBUCO, 2002).

Delizoicov, Angotti e Pernambuco (2002, p. 153) pontuam que

Tornar a aprendizagem dos conhecimentos científicos em sala de aula num desafio prazeroso é conseguir que seja significativa para todos, tanto para o professor quanto para o conjunto dos alunos que compõem a turma. É transformá-la em um projeto coletivo, em que a aventura da busca do novo, do desconhecido, de sua potencialidade, de seus riscos e limites seja oportunidade para o exercício e o aprendizado das relações sociais e dos valores.

Para isso, a abordagem de conteúdos relacionados as Ciências Naturais devem partir de temas significativos e expor os conhecimentos pelos processos passados, por sua história e por seus procedimentos, compreendendo-os como resultado de ações, tornando o aprendizado um modo de conquista pessoal e coletiva com intuito de uma vida melhor, utilizando o conhecimento da Ciência como um dos meios de se atuar e de se explicá-lo de forma crítica (DELIZOICOV; ANGOTTI; PERNAMBUCO, 2002).

\section{Metodologias variadas no ensino de ciências}

Devido à abrangência e natureza dos objetos de estudo da área de Ciências, seus meios de ensino podem ser desenvolvidos de formas diversas, norteando o ensino para o conhecimento dos fenômenos da natureza, compreendendo o ser humano e as tecnologias de maior proximidade e mais distantes, tanto no espaço quanto no tempo (BRASIL, 1997). 
No desenvolvimento de atividades com metodologias variadas, "a efetividade das estratégias depende do contexto da aprendizagem e das características dos estudantes" (PRIGOL; GIANNOTTI, 2008, p. 2), pois

se automonitoradas [atividades de ensino construtivistas] pelo sujeito da aprendizagem, essas atividades podem proporcionar ao educando um controle eficiente do processo, o que desencadeará no indivíduo um maior índice de satisfação com o próprio desempenho (ZULIANI; ÂNGELO, 2001, p. 78).

Delizoicov, Angotti e Pernambuco (2002) relatam que meios paradidáticos precisam estar mais presentes e de forma sistemática no meio educacional, pois mais que presentes, é essencial seu uso de maneira crítica e consciente pelo docente de Ciências em todos os níveis de escolaridade, sendo que articulações, determinações e interesses só alertam ainda mais para a utilização dos mesmos de forma crítica e consciente.

Propiciar o novo em Ciências Naturais é trazer para o ambiente escolar as notícias do jornal, as novidades da Internet, é visitar museus e exposições de divulgação científica, como parte da rotina da vida escolar. O próprio espaço físico pode ser uma forma de criar demandas: murais, jornais murais; nas bibliotecas, revistas e jornais de divulgação científica, livros instigantes de ficção científica ou mesmo de literatura; filmes nas videotecas; exposições de curiosidades e demonstrações, não só na sala de aula de Ciências, mas nos pátios e corredores - para mencionar somente algumas dessas estratégias. Feiras de ciências, semanas culturais, visitas a parques e museus, conferências, idas a congressos, [...] podem fazer parte da agenda permanente de uma escola, provocando novos desafios a serem enfrentados na sala de aula (DELIZOICOV; ANGOTTI; PERNAMBUCO, 2002, p. 153154).

A utilização de diferentes metodologias e das consequentes atividades realizadas através destas são fontes de motivação dos alunos, possibilitandoos atender no que mais the interessam e necessitam conhecer (SANMARTí, 2002; BUENO, 2003). Conforme os autores citados, essa pluralidade de estratégias abre um leque maior de oportunidades na busca de se construir o conhecimento, além de fornecer meios de melhor entendimento do conteúdo para maior quantidade de alunos. 


\section{Metodologia}

A pesquisa em questão parte da abordagem quali-quantitativa e exploratória. O estudo foi conduzido no município de lbitirama, que compõe a microrregião do Caparaó, correspondente ao estado do Espírito Santo. Para tal, foram selecionadas as escolas que atendessem aos alunos de Ensino Fundamental dos Anos Finais.

A coleta de dados foi por meio de questionário contendo questões de múltipla escolha no qual foram direcionados aos professores da disciplina de Ciências das escolas municipais e estaduais do município de Ibitirama.

Para averiguar a frequência de utilização dos recursos didáticos de cada metodologia pesquisada, optou-se por uma escala de 1 a 5 , sendo que 1 deveria ser utilizado para os recursos menos utilizados e 5 para os recursos mais utilizados.

O público alvo do respectivo estudo foi composto de cinco professores de Ciências, distribuídos nas quatro escolas públicas participantes. Os profissionais participantes possuem pós-graduação lato sensu e quatro deles atuam entre 1 e 5 anos e um participante entre 5 e 10 anos.

\section{Resultados e discussão}

Observa-se que dos 5 professores entrevistados, 16\% deles optaram pelas enciclopédias temáticas como recurso de maior utilização em forma de texto; $13 \%$, livros de divulgação ou ficção científica; $25 \%$, matérias de jornais ou revistas; $20 \%$, folhetos de origem diversa (museus, postos de saúde, organizações não-governamentais, empresas, etc.); e $26 \%$, livros paradidáticos (Gráfico 1). Verificou-se que livros paradidáticos, seguidos de matérias de jornais e revistas, são os recursos didáticos mais utilizados em forma de textos nas intervenções pedagógicas.

Rondow Júnior e Oliveira (2009) tratam os livros paradidáticos como instrumentos de grande proveito para o trabalho do educador, pois, podem levar o discente ao conhecimento de novas informações e questionamentos que não estão presentes nos livros didáticos. Viana e Silva (2002) abordam a importância da utilização de jornais pelas possibilidades de trabalho que 
apresentam, e a possibilidade de se posicionar criticamente a respeito de informações.

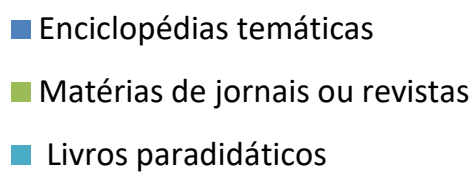

- Livros paradidáticos

- Livros de divulgação ou ficção científica

- Folhetos de origem diversa

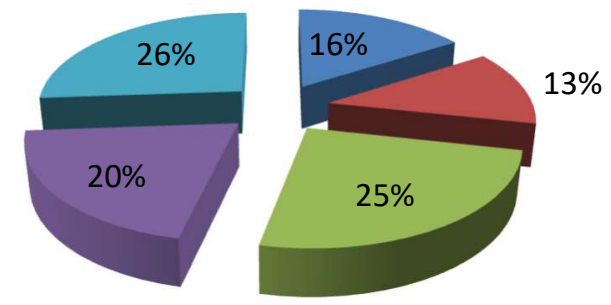

FIGURA 1: Frequência de utilização dos recursos dispostos em forma de textos

Identificou-se que dos 5 professores, $9 \%$ deles optaram pelo microscópio como recurso de maior utilização na metodologia observação; $6 \%$, telescópio, 23\%; fotos, 26\%; filmes; 19\%, gravuras; e, 17\%, gravações sonoras (CD) (Figura 2).

Deste modo, constata-se que o recurso mais utilizado são os filmes e, logo após, as imagens. Vidal e Rezende Filho (2009) abordam a utilização de filmes devido à sensibilização que os mesmos causam nas temáticas, além de repassarem informações e valores, construindo assim o conhecimento.

Microscópio
Filmes

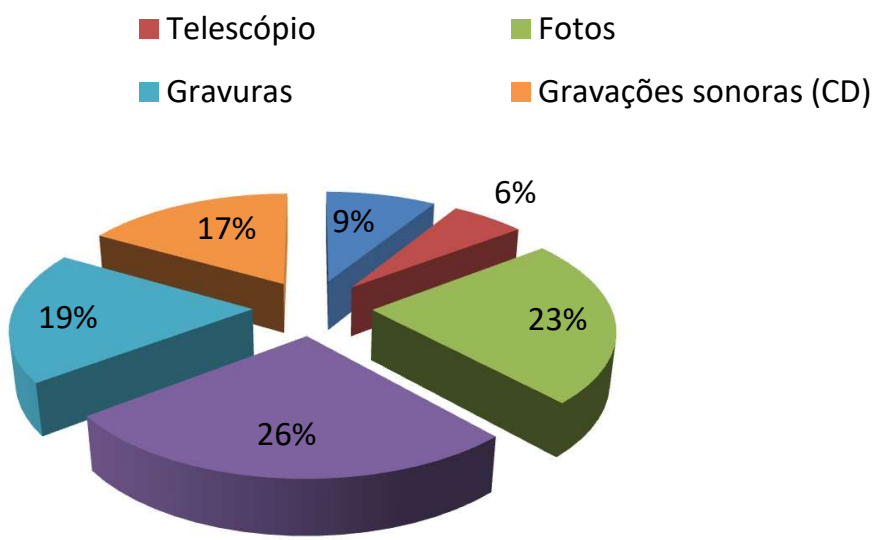

FIGURA 2: Frequência de utilização dos recursos relacionados à metodologia observação Aponta-se que dos 5 professores, 34\% deles optaram pelos ambientes naturais como opção de aulas na metodologia trabalho de campo de maior 
frequência; $22 \%$, áreas de preservação ou conservação, $23 \%$, áreas de produção primária (plantações), e, 21\%, exposições científicas, museus, indústrias (Figura 3). Verifica-se, desta forma, que os ambientes naturais são a forma de trabalho de campo mais aplicada e exposições científicas, museus, indústrias, tiveram a menor frequência de aplicação.

Seneciato (2002) cita a importância da aplicação de aulas de campo em ambientes naturais devido à gama de elementos naturais que cada ambiente natural possui, ao entendimento prático da integração dos seres vivos, tanto quanto suas formas de vida e da melhor compreensão dos fatores bióticos e abióticos ali ocorridos. O autor ainda ressalta as emoções e sensações surgidas nos discentes no decorrer das aulas em ambientes naturais, aspectos que favorecem o bem-estar dos mesmos, e que despertam o interesse e participação do então momento de aprendizagem.

Ambientes naturais

口 Áreas de preservação ou conservação

Áreas de produção primária (plantações)

— Exposições científicas, museus, indústrias

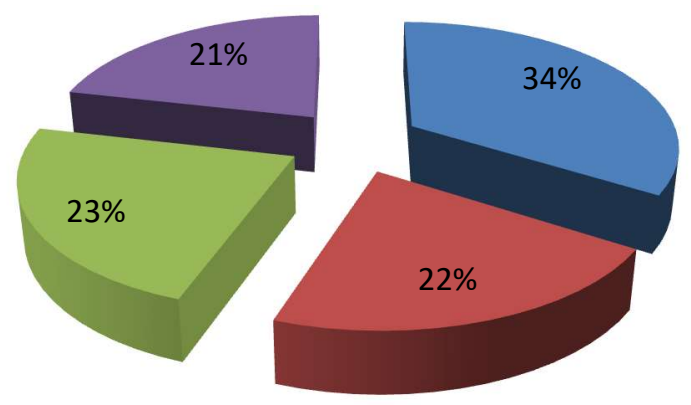

FIGURA 3: Frequência de aplicação das opções de aula na metodologia trabalho de campo

Observa-se que dos 5 professores, 40\%, pela opção A e B, que, respectivamente, são utilização de um protocolo ou guia de experimento e procedência à demonstração de um fenômeno, e, discussão e manipulação de materiais pelos próprios alunos; $20 \%$, utilização de um protocolo ou guia de experimento; e, 40\% não possuem laboratório. Nenhum deles optou apenas pela discussão e manipulação de materiais pelos próprios alunos (Figura 4). De 
tal modo, percebe-se que grande parte das escolas não possui laboratório, e a outra parte de igual proporção utiliza das duas formas de aplicação citadas para a metodologia experimentação.

Pesquisas realizadas por Krasilchik (1987), Carvalho et al. (2003), Possobom, Okada e Diniz (2003), Laburú, Barros e Kanbach (2007), Feitosa, Leite e Freitas (2011) mostram que a realidade das escolas é a falta de instalações adequadas, como citado pelos professores perguntados na presente pesquisa.

Analisando as opções $A$ e $B$ tida pelos professores (utilização de um protocolo ou guia de experimento e procedência à demonstração de um fenômeno, e, discussão e manipulação de materiais pelos próprios alunos), Giani (2010) trata dessa forma de aplicação da metodologia experimentação ressaltando a importância de atividades práticas "abertas" que possibilitem aos discentes a participação durante os processos realizados; discute, também, sobre a utilização de protocolos experimentais como formas apenas executadas pelos alunos e que na maioria das vezes não refletem a aprendizagem sobre o que está sendo feito.
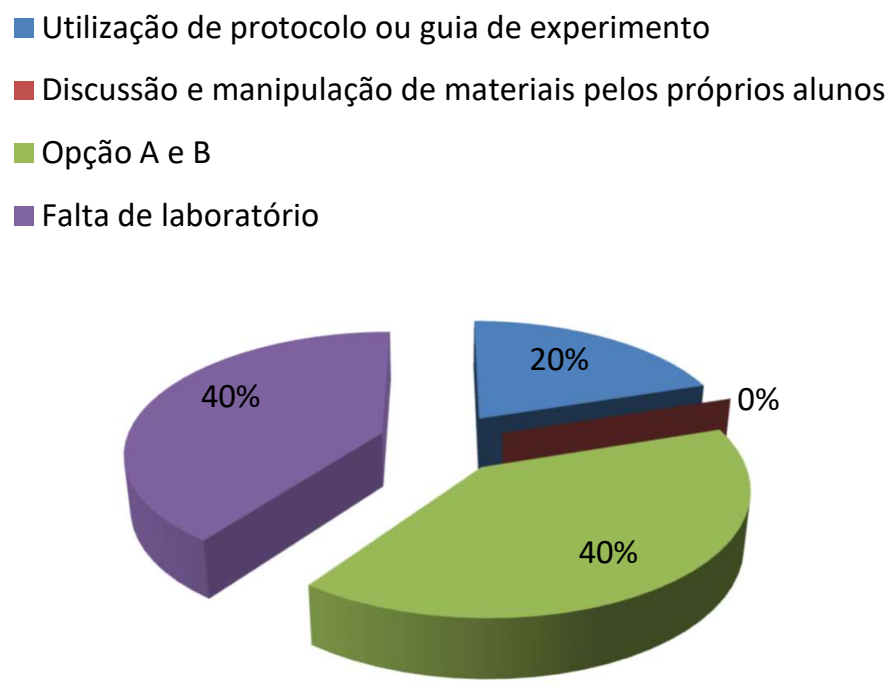

FIGURA 4: Formas de utilização da metodologia experimentação

Verifica-se que dos 5 professores, $75 \%$ deles optaram pelos sites científicos como recurso de maior frequência de utilização na metodologia informática; e, 25\% das escolas não possuem laboratório de informática (Figura 
5). Aponta-se, deste modo, uma utilização quase total de sites científicos e a falta de laboratório de informática.

$\begin{array}{ll}\square \text { Microsoft Office } & \text { Sites científicos } \\ \text { Softwares de jogos científicos } & \text { Enciclopédias virtuais }\end{array}$

não possui laboratório de informática

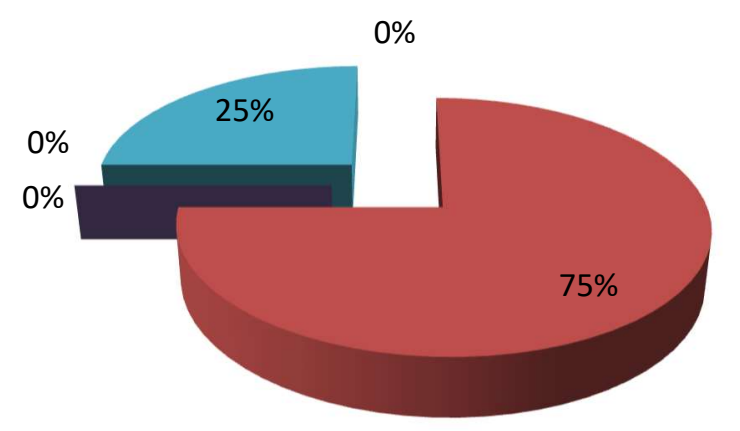

FIGURA 5: Frequência de utilização dos recursos dispostos na metodologia informática

\section{Considerações finais}

A partir da pesquisa realizada, pode-se verificar a variação existente na utilização de diferentes metodologias no ensino de Ciências pelos professores de Ensino Fundamental dos Anos Finais do município de Ibitirama - ES.

Por meio do estudo realizado, aponta-se que diferentes recursos são utilizados pelos professores de Ciências no decorrer do processo de ensinoaprendizagem, entretanto, nota-se a preferência por determinados recursos metodológicos, o que se deve a mais fácil preparação e aplicabilidade dos mesmos.

Ressalta-se ainda que dada variação na utilização de metodologias variadas deve-se aos recursos disponíveis para uso nas escolas onde atuam e à necessidade de uso dos mesmos de modo a atender as temáticas trabalhadas no decorrer das aulas.

Por fim, considera-se a importância da utilização de diferentes metodologias para o desenvolvimento do processo de ensino-aprendizagem em Ciências, buscando a formação crítica e reflexiva do educando, possibilitando ao mesmo, a aquisição de informações para a elaboração e, certas vezes, até mesmo, a reelaboração de seus conceitos, costumes, 
atitudes, etc.; sendo que este processo reflexivo é necessário para a ampliação de sua autonomia atrelado a obtenção do conhecimento.

\section{Referências}

BRASIL. Ministério da Educação. Base Nacional Comum Curricular. Brasília: MEC, 2018.

Secretaria de Educação Fundamental. Parâmetros Curriculares Nacionais: Ciências Naturais. Brasília: MEC/SEF, 1997.

Secretaria de Educação Fundamental. Parâmetros curriculares nacionais: terceiro e quarto ciclos do ensino fundamental: introdução aos parâmetros curriculares nacionais. Brasília: MEC/SEF: 1998.

BUENO, A. La construcción del conocimiento científico y los contenidos de ciencias. In: ALEIXANDRE, M. P. J. (Coord.) Enseñar ciencias. Barcelona: Editorial GRAÓ, p. 33-54, 2003.

CARVALHO, W. L. P. et al. O laboratório didático e o desenvolvimento do conhecimento pedagógico do conteúdo de professores de química. In: GARCIA, W. G.; GUEDES, A. M. (Org.). Núcleos de ensino. São Paulo: Unesp, Pró-Reitoria de Graduação, 2003. p. 306-317.

DELIZOICOV, D.; ANGOTTI, J.; PERNAMBUCO, M. Ensino de Ciências: fundamentos e métodos. São Paulo: Cortez, 2002.

FEITOSA, R.; LEITE, R.; FREITAS, A. "Projeto aprendiz": interação universidade-escola para realização de atividades experimentais no Ensino Médio. Ciência \& Educação, Fortaleza, v. 17, n. 52, p. 301-320, 2011.

GIANI, K. A experimentação no ensino de ciências: possibilidades e limites na busca de uma aprendizagem significativa, 2010. Dissertação (Mestrado em Ensino de Ciências) - Programa de Pós-Graduação em Ensino de Ciências, Universidade de Brasília, Brasília, 2010.

KRASILCHIK, M. O professor e o currículo das ciências. São Paulo: EDUSP, 1987.

LABURÚ, C. E.; BARROS, M. A.; KANBACH, B. G. A relação com o saber profissional do professor de física e o fracasso da implementação de atividades experimentais no ensino médio. Investigações em Ensino de Ciências, Porto Alegre, v. 12, n. 3, p. 305-320, 2007.

MALAFAIA, G.; RODRIGUES, A. Uma reflexão sobre o ensino de ciências no nível fundamental da educação. Ciência \& Ensino, v. 2, n. 2, p. 1-9, 2008.

MOURA, G.; VALE, J. O ensino de ciências na $5^{\mathrm{a}}$ e na $6^{\mathrm{a}}$ séries da Escola Fundamental. In: NARDI, Roberto (ORG.). Educação em ciências: da pesquisa à prática docente. São Paulo: Escrituras, 2001. p. 135-143. 
POSSOBOM, C. C. F.; OKADA, F. K.; DINIZ, R. E. S. Atividades práticas de laboratório no ensino de biologia e ciências: relato de uma experiência. In: GARCIA, W. G.; GUEDES, A. M. (Orgs.). Núcleos de ensino. São Paulo: Unesp, Pró-Reitoria de Graduação, 2003. p. 113-123.

PRIGOL, S.; GIANNOTTI, S. A importância da utilização de práticas no processo de ensino-aprendizagem de ciências naturais enfocando a morfologia da flor. Trabalho apresentado no $1^{\circ}$ Simpósio Nacional de Educação/ XX Semana da Pedagogia, Cascavel, 2008.

RONDOW JÚNIOR, N.; OLIVEIRA, L. O ensino de termodinâmica na perspectiva sociointeracionista: proposta de um livro paradidático. Trabalho apresentado no VII Encontro Nacional de Pesquisa em Educação em Ciências, Florianópolis, 2009.

SANMARTÍ, N. Didáctica de las ciencias en la educación secundaria obligatoria. Madrid: Sintesis Educación, 2002.

VIANA, F.; SILVA, Y. O jornal e a prática pedagógica. In: CHIAPPINI, L. Aprender e ensinar com textos não escolares. 5. ed. São Paulo: Cortez, 2002.

VIDAL, F.; REZENDE FILHO, L. Utilização de recursos audiovisuais (RAVs) na educação em ciências: uma análise dos trabalhos publicados nos I, II e III EREBIO (SE) e I ENEBIO. Trabalho apresentado no VII Encontro Nacional de Pesquisa em Educação em Ciências, Florianópolis, 2009.

ZULIANI, S.; ÂNGELO, Antonio C. A utilização de metodologias alternativas: o método investigativo e a aprendizagem de química. In: NARDI, R. (ORG.). Educação em ciências: da pesquisa à prática docente. São Paulo: Escrituras, 2001, p. 69-79.

\section{Sobre os Autores}

\section{Manoel Augusto Polastreli Barbosa}

manoelpolastreli@hotmail.com

Mestre em Ensino, Educação Básica e Formação de Professores (PPGEEDUC) - UFES (Campus Alegre). Professor da Educação Básica de Conceição do Castelo/ES.

\section{Pedro José Garcia Júnior}

juniorgarciah@hotmail.com

Professor da Educação Básica de Venda Nova do Imigrante/ES. Graduado em Ciências Biológicas e Pedagogia. Pós-Graduado em Prática e processos educativos; Educação ambiental; Arte; Design Educacional; e, Oratória, Transversalidade e Didática da Fala para a Formação de Professores. PósGraduando no Curso de Especialização Ciência é 10! (UFES/CAPES). 